\title{
Sex, bugs and Haldane's rule: the nematode genus Pristionchus in the United States
}

\author{
Matthias Herrmann, Werner E Mayer and Ralf J Sommer*
}

Address: Max Planck Institute for Developmental Biology, Department of Evolutionary Biology, Tübingen, Germany

Email: Matthias Herrmann - matthias.herrmann@tuebingen.mpg.de; Werner E Mayer - werner.mayer@tuebingen.mpg.de; Ralf J Sommer* - ralf.sommer@tuebingen.mpg.de

* Corresponding author

Published: 12 September 2006

Frontiers in Zoology 2006, 3:14 doi:10.1 I86/1742-9994-3-14
Received: 14 June 2006

Accepted: 12 September 2006

This article is available from: http://www.frontiersinzoology.com/content/3/1/14

(c) 2006 Herrmann et al; licensee BioMed Central Ltd.

This is an Open Access article distributed under the terms of the Creative Commons Attribution License (http://creativecommons.org/licenses/by/2.0), which permits unrestricted use, distribution, and reproduction in any medium, provided the original work is properly cited.

\begin{abstract}
Background: The nematode Pristionchus pacificus has been developed as a satellite organism in evolutionary developmental biology for comparison to Caenorhabditis elegans. Comparative studies have revealed major differences in the regulation of developmental processes between $P$. pacificus and $C$. elegans. To place evolutionary developmental biology and the observed developmental differences between species in a comprehensive evolutionary context, such studies have to be complemented with ecological aspects. Knowledge about the ecology of the organism in question might indicate specific environmental conditions that can result in developmental adaptations and could account for species differences in development. To this end, we have started to investigate the ecology of Pristionchus nematodes. In recent field studies in Western Europe we found six Pristionchus species that are closely associated with scarab beetles and the Colorado potato beetle. This Pristionchus - beetle association provides the unique opportunity to combine research in evolutionary developmental biology with ecology. However, it remains unknown how general these findings from Europe are on a global scale.
\end{abstract}

Results: Here, we describe the Pristionchus species associated with scarab and Colorado potato beetles in the Eastern United States and show striking transatlantic differences and unexpected evolutionary and ecological patterns. Twohundredeighty of 285 (98\%) isolates from American scarab beetles belong to five Pristionchus species, all of which are different from the European species. We describe four of them as novel Pristionchus species. The five American Pristionchus species fall into a single phylogenetic clade and have a male-female (gonochoristic) mode of reproduction, whereas the majority of European isolates are hermaphroditic. Crosses between the two most closely related species, $P$. aerivorus and P. pseudaerivorus n. sp., follow Haldane's rule in that heterogametic $\mathrm{FI}$ males are inviable. We observed $P$. aerivorus and $P$. pseudaerivorus $\mathrm{n}$. sp. coexisting on the same scarab beetle and obtained two cases of FI hybrids from wild beetles. Finally, the Colorado potato beetle is associated with the same nematode, $P$. uniformis in the United States and Europe. Given the introduction of the Colorado potato beetle to Europe in 1877, our results suggest that $P$. uniformis was introduced together with its beetle vector.

Conclusion: Taken together, the Pristionchus - beetle association provides a powerful tool for studying biodiversity, biogeography, speciation and species invasion on a global scale. 


\section{Background}

The diplogastrid nematode Pristionchus pacificus has been developed as a satellite organism in evolutionary developmental biology [1]. P. pacificus is a hermaphroditic species that can feed on E. coli and has a 3-4 day generation time $\left(20^{\circ} \mathrm{C}\right)$ [2]. Original studies in $P$. pacificus concentrated on the developmental, genetic and molecular analysis of sex determination, vulva and gonad formation [3]. More recently, a genomic initiative including the generation of a genetic linkage map and a physical map has complemented the developmental and genetic studies [4,5]. A whole genome sequencing project is currently ongoing and should result in a draft of the complete genome sequence in the near future [1].

In general, little is known about the ecology of the nematode species used as laboratory organisms, such as $P$. pacificus and C. elegans. For example, the environmental niche of the model organism C. elegans is largely unknown and only very recently did several studies indicate that $C$. elegans occurs predominantly in compost heaps $[6,7]$. We have recently shown that nematodes of the genus Pristionchus live in close association with scarab beetles and the Colorado potato beetle (CPB) in Western Europe [8]. Intensive samplings in 2004 and 2005 generated 371 isolates that fell into six species, most of which are morphologically indistinguishable from one another. The two hermaphroditic species $P$. entomophagus and $P$. maupasi accounted for 226 of these 371 (60\%) isolates and occurred on dung beetles and cockchafers, respectively. However, the satellite organism P. pacificus was neither observed on scarab beetles nor on the CPB in Western Europe.

In total, 27 species of the genus Pristionchus are described in the literature, but only four of these descriptions are younger than 1958 and many are from the 19th century [9]. Also, many of these descriptions are rather short and lack illustrations. Type material does not exist in most cases - either because it never existed or because it got lost. Furthermore, it has long been known that morphometric values of Pristionchus species change during culture under laboratory conditions [10]. Taking this high phenotypic plasticity into account, the 27 species descriptions contain most likely a number of synonyms. Facing all of these problems of "classical" taxonomy, we have started to use a novel methodology to investigate the biodiversity and phylogeny of Pristionchus nematodes. Following the isolation of Pristionchus nematodes from wild caught beetles, we establish isogenic female lines. These isogenic female lines are first processed by SSU sequence analysis for molecular barcoding. Previous studies have indicated that this method is robust and provides a clear indication for species identity or evidence for the existence of a novel species [8]. To confirm the species identification by molecular barcoding we perform mating experiments of a new isolate with the reference strain of the representative species. For the reference strain of a novel species, morphometric measurements are provided in addition to the molecular sequence tag. Also, a frozen stock collection has been established, type material is delivered to museums and strains are available upon request. We strongly believe that this comprehensive methodology - molecular barcoding, mating experiments, morphometric measurements, frozen stock collection and type material at museum collections - provides the optimal tool for species identification and analysis in this group of nematodes.

In the present study we surveyed the association of Pristionchus species with scarab beetles and the CPB in the Eastern United States, particularly in the states of New York, Massachusetts, Nebraska, Ohio, Iowa, Texas, and Kansas. The two studies indicate striking differences in the species composition, mode of reproduction and speciation frequency of Pristionchus species on the two continents. More than $98 \%$ of the Pristionchus isolates from the Eastern United States represent five species, all of which are unknown from Europe. Given the rationale described above, we describe four novel Pristionchus species. These results establish Pristionchus as a nematode model system for biogeography and biodiversity and represent an important difference to the biogeography of Caenorhabditis species. In addition, the analysis of Pristionchus species in the US provided two unexpected cases that help to establish Pristionchus as a future model system in two additional areas of evolutionary biology and ecology, namely speciation and species invasion. Crosses between the two most closely related American species, Pristionchus aerivorus and Pristionchus pseudaerivorus n. sp., result in inviable males following Haldane's rule. Haldane's rule states that in hybrids between diverging species the sterile, absent or underrepresented offspring is of the heterogametic sex [11]. Finally, the CPB is associated with the same nematode, Pristionchus uniformis in the US and Europe. Given the introduction of the CPB to Europe in 1877 , these results suggest that $P$. uniformis was introduced together with its beetle vector. Species invasion is a common phenomenon in contemporary ecology and biogeography and the $P$. uniformis case reported in this study might represent a useful tool for future genetic and molecular studies on species invasion.

\section{Results \\ Five of the Pristionchus species found on scarab beetles in the US do not occur in Europe}

To determine if $P$. pacificus and other species of the genus Pristionchus are associated with scarab beetles in the United States, we analyzed beetles from Massachusetts, New York, Ohio, Iowa, Kansas, Texas, and Nebraska. The 
scarab beetle fauna differs between North America and Europe. For example, the cockchafer Melolontha melolontha and the dung beetle Geotrupes stercorosus that host the predominant European Pristionchus species are not known from North America. However, the subfamily Melolonthinae, which includes the june beetles and chafers, contains more than 500 species in North America, some of which are serious pests [12]. We used the same sampling strategies in Europe and the United States and collected scarab beetles from the US that are comparable with those obtained in our European study. However, we have not been able to sample identical species on both continents. In total, we investigated 1241 beetles of more than 15 genera yielding 285 Pristionchus isolates (Fig. 1, Table 1). SSU sequence analysis and mating experiments of the 285 isolates revealed that they fall into seven species, two of which were known to us (Fig. 2). We obtained

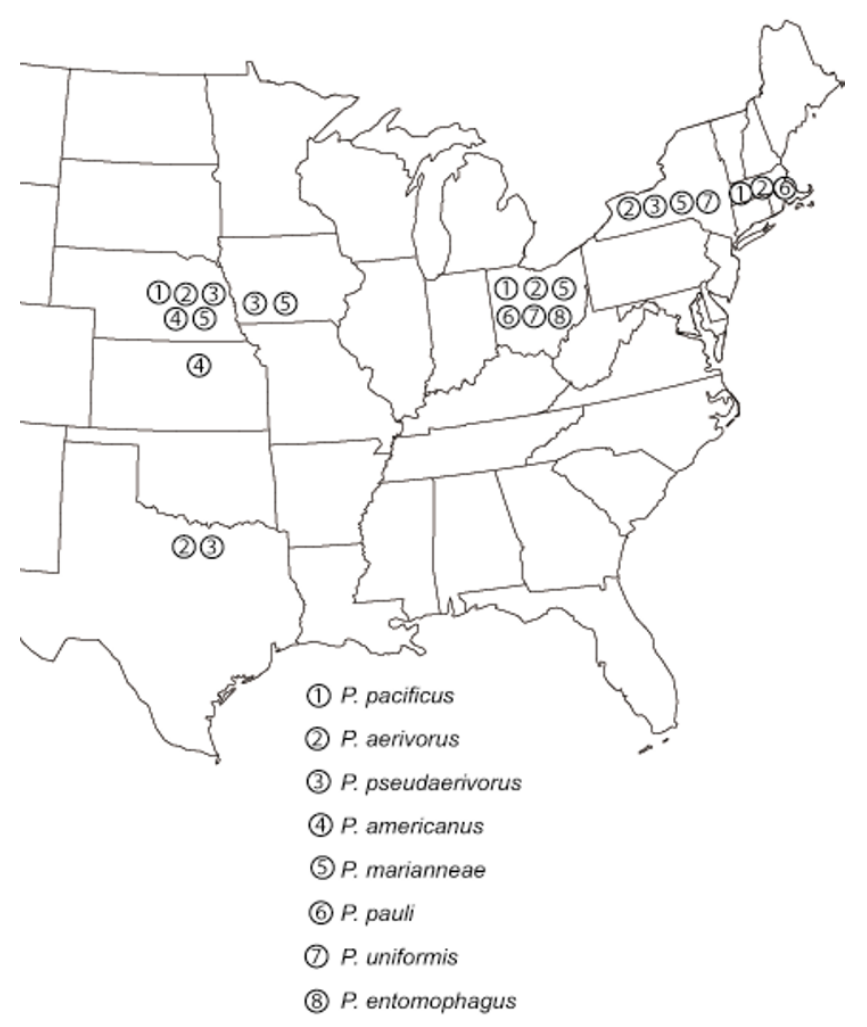

Figure I

Map of the Eastern US showing the distribution of sampled Pristionchus species. Material has been obtained from the following sampling sites: Massachusetts (Two locations: Carver and Centerville), New York (six locations: Bellona, Waterloo, Hoover farm, golf court I and II, Geneva), Ohio (One location : Wooster), lowa (One location: near Bellevue, Nebraska), Kansas (One location: Greensburg), Texas (One location: Austin), and Nebraska (five locations: Lincoln: pioneer park, wilderness park, nine mile prairie; Bennett, Nemaha). two strains of $P$. entomophagus (both from beetles from Ohio), a hermaphroditic species that is one of the most common Pristionchus species in Europe [8]. We also found $P$. pacificus, but in no more than three beetle samples, one from Ohio, one from Nebraska and one from Massachusetts. Surprisingly, the remaining 280 (98\%) isolates represent five Pristionchus species, which had up to then neither been found by beetle sampling in Western Europe [8] nor by previous soil sampling in the United States [13].

Nematode species of the genus Pristionchus have little diagnostic morphological characters and usually show overlapping ranges of morphometric values [14,8]. Prior to our own studies on P. pacificus, only one Pristionchus species, P. aerivorus, was described for North America by Cobb in 1916 [9,15]. All previously obtained strains of P. pacificus from North America result from soil samples taken by various researchers $[8,13]$. It is important to note that all of these soil-derived P. pacificus strains represent random findings within a sampled locality. P. pacificus was a rare nematode in these soil samples and multiple isolates from the same soil sample are not available.

Morphometric analysis revealed that the most common species in our analysis is very similar to $P$. aerivorus (Table 2 ). Thus, we have classified this species as $P$. aerivorus. The four other species are described as novel species and we provide morphological measurements, molecular SSU sequence data, the results of mating experiments and species designations for all of them (Fig. 2, Table 2, see species diagnosis below). The reference strains of all species are available as living cultures and frozen stocks in our laboratory and can be provided to other researchers upon request. Also, type material has been delivered to museums. Together, these five species account for the majority of isolates from scarab beetles (Table 1). Specifically, we obtained $P$. aerivorus (85 isolates), P. pseudaerivorus $\mathrm{n}$. sp. (71 isolates), P. marianneae n. sp. (45 isolates), P. pauli $\mathrm{n}$. sp. (35 isolates) and $P$. americanus $n$. sp. ( 1 isolate) in the US scarab beetle survey. In the following, we provide the diagnoses for the four novel Pristionchus species:

\section{Pristionchus marianneae n. sp}

Diagnostic character: The species is characterized by a 471 bp sequence of a $1 \mathrm{~kb}$ fragment of the small subunit ribosomal RNA gene (SSU) that was amplified by PCR with the primers shown in Materials and Methods. This SSU sequence is distinct from the SSU sequence of all other Pristionchus species, but is identical between all isolates of P. marianneae. The sequence is shown in Fig. 2.

GenBank accession code: DQ419901 


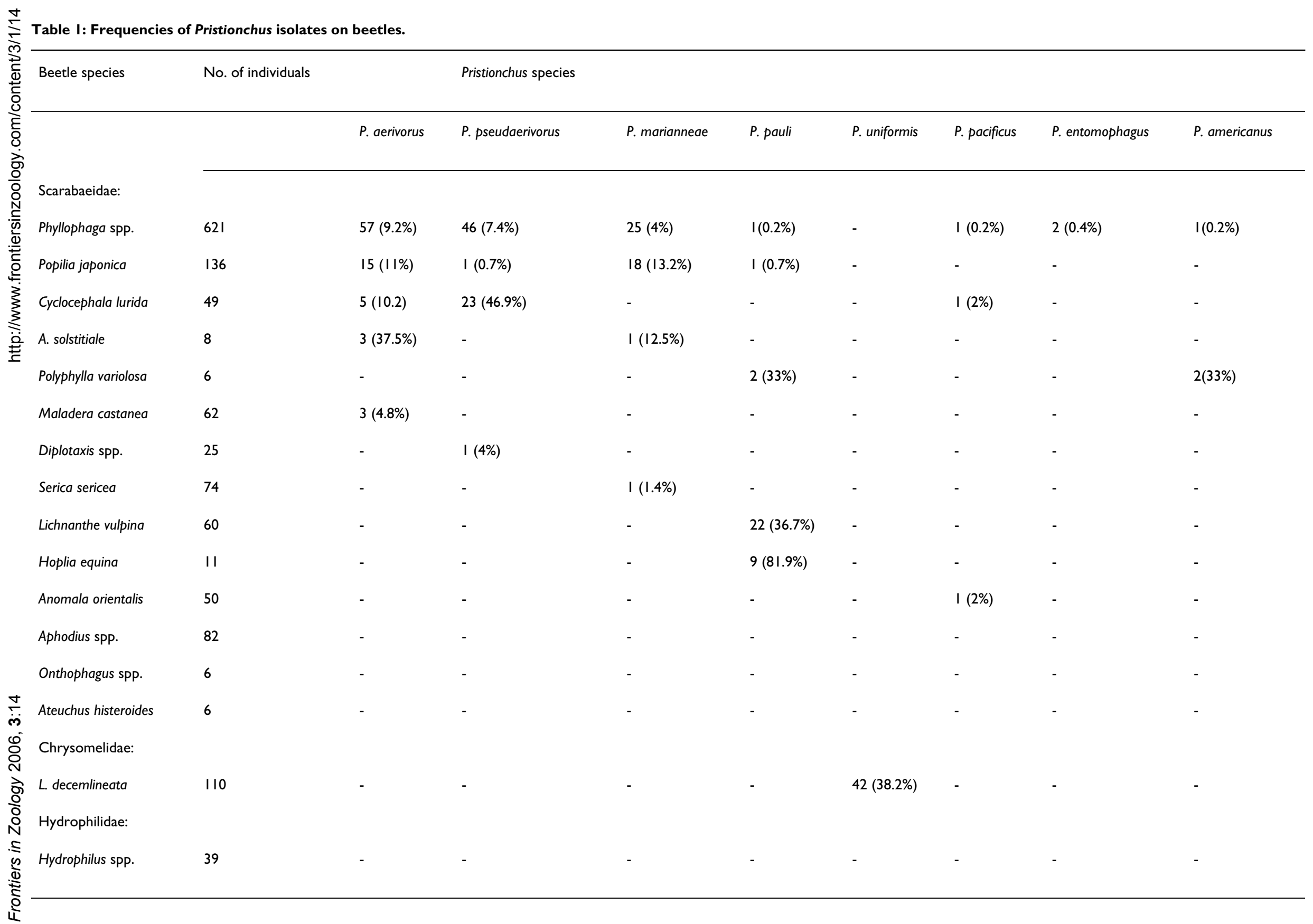




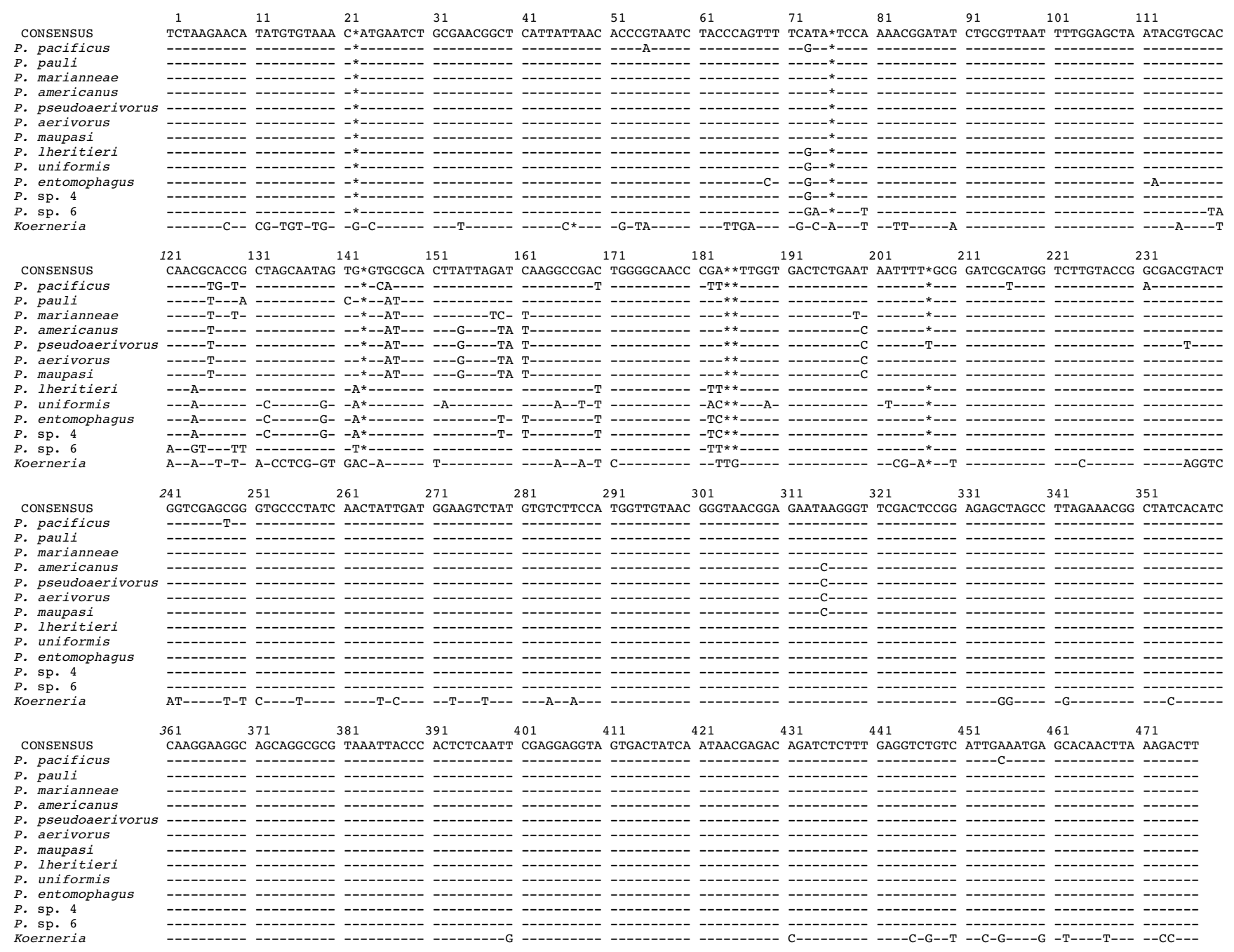

\section{Figure 2}

Alignment of SSU sequences. Sequences of I 3 Pristionchus and one Koerneria species were aligned manually. Dashes (-) indicate identity to the majority consensus sequence at the top; asterisks $\left(^{*}\right)$ indicate alignment gaps. Numbering refers to the SSU segment obtained in this study. The sequences have been submitted to the GenBank database and are available under the accession codes DQ270018-DQ270025 and DQ419900-DQ419904.

A second diagnostic character is provided by mating experiments. P. marianneae males mate with females of other isolates but not with females/hermaphrodites of other species.

Morphological measurements: see Table 2

Type host and locality: On Popilia japonica (Coleoptera: Scarabaeidae) near Geneva, New York, United States of America.

Etymology: R. J. S and M. H. want to dedicate this species to their mothers.
Frozen strain number: RS5108

Holotype: One male permanent slide No: SMNK-NEMAT0022 (Natural History Museum Karlsruhe, Germany)

Paratypes: One male and one female permanent slide No: SMNK-NEMA-T0023; One male and one female permanent slide No: SMNK-NEMA-T0024

\section{Pristionchus pauli $n$. sp}

Diagnostic character: The species is characterized by a 471 bp sequence of a $1 \mathrm{~kb}$ fragment of the small subunit ribosomal RNA gene ( $S S U$ ) that was amplified by PCR with the 


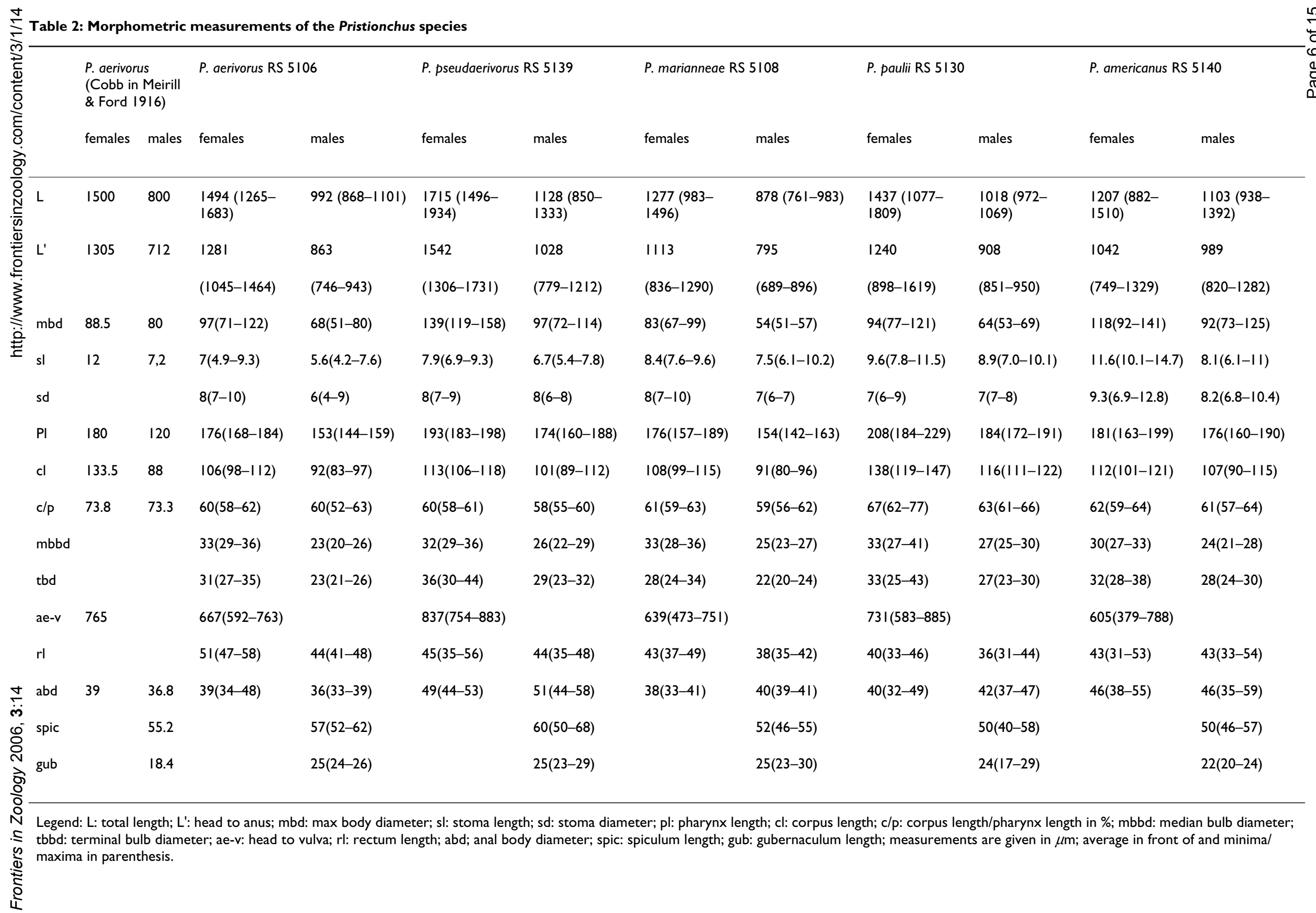


primers shown in Materials and Methods. This SSU sequence is distinct from the $S S U$ sequence of all other Pristionchus species, but is identical between all isolates of $P$. pauli. The sequence is shown in Fig. 2.

GenBank accession code: DQ419900

A second diagnostic character is provided by mating experiments. P. pauli males mate with females of other isolates but not with females/hermaphrodites of other species.

Morphological measurements: see Table 2

Type host and locality: On Lichnanthe vulpina (Coleoptera: Scarabaeidae) in Carver, Massachusetts, United States of America

Etymology: M. H. wants to dedicate this species to Dr. Paul S. Robbins, an outstanding beetle expert and true friend.

Frozen strain number: RS5130

Holotype: One male permanent slide No: SMNK-NEMAT0025 (Natural History Museum Karlsruhe, Germany)

Paratypes: One male and one female permanent slide No: SMNK-NEMA-T0026; One male and one female permanent slide No: SMNK-NEMA-T0027

\section{Pristionchus americanus $n$. sp}

Diagnostic character: The species is characterized by a $471 \mathrm{bp}$ sequence of a $1 \mathrm{~kb}$ fragment of the small subunit ribosomal RNA gene ( $S S U$ ) that was amplified by PCR with the primers shown in Materials and Methods. This $S S U$ sequence is distinct from the SSU sequence of all other Pristionchus species. The sequence is shown in Fig. 2.

GenBank accession code: DQ419904

$P$. americanus males do not mate successfully with females/hermaphrodites of other species.

Morphological measurements: see Table 2

Type host and locality: On Polyphylla fullo (Coleoptera: Scarabaeidae) in Centerville, Massachusetts, United States of America

Etymology: This species has been found only in the United States of America so far. Frozen strain number: RS5140
Holotype: One male permanent slide No: SMNK-NEMAT0019 (Natural History Museum Karlsruhe, Germany)

Paratypes: One male and one female permanent slide No: SMNK-NEMA-T0020; One male and one female permanent slide No: SMNK-NEMA-T0021

\section{Pristionchus pseudaerivorus $n$. $s p$}

Diagnostic character: The species is characterized by a 472 bp sequence of a $1 \mathrm{~kb}$ fragment of the small subunit ribosomal RNA gene ( $S S U$ ) that was amplified by PCR with the primers shown in Materials and Methods. This SSU sequence is distinct from the $S S U$ sequence of all other Pristionchus species, but is identical between all isolates of P. pseudaerivorus. The sequence is shown in Fig. 2.

GenBank accession code: DQ419902

Morphological measurements: see Table 2

Type host and locality: On Phyllophaga sp. (Coleoptera: Scarabaeidae) near Lincoln, Nebraska, United States of America.

Etymology: The species is very similar in respect to morphological measurements and molecular sequence to $P$. aerivorus. Mating experiments revealed that crosses between $P$. pseudaerivorus and $P$. aerivorus can result in sterile females.

Frozen strain number: RS5139

Holotype: One male permanent slide No: SMNK-NEMAT0028 (Natural History Museum Karlsruhe, Germany)

Paratypes: One male and one female permanent slide No: SMNK-NEMA-T0029; One male and one female permanent slide No: SMNK-NEMA-T0030

\section{Pristionchus species sampled on American scarab beetles are predominantly gonochoristic}

The result of the US survey indicates a striking difference in the mode of reproduction of North American and European beetle associated Pristionchus species. $P$. aerivorus, $P$. pseudaerivorus n. sp., P. pauli n. sp., P. marianneae n. sp. and $P$. americanus $\mathrm{n}$. sp. are gonochoristic (male/female) species and account for $98 \%$ of the isolates from scarab beetles (Fig. 3). In contrast, more than $60 \%$ of the isolates from scarab beetles in Western Europe belong to two hermaphroditic species, $P$. maupasi and $P$. entomophagus, respectively (Fig. 3) [8]. Thus, North America and Europe differ in the Pristionchus species associated with scarab beetles and in the mode of reproduction of these nematodes. 

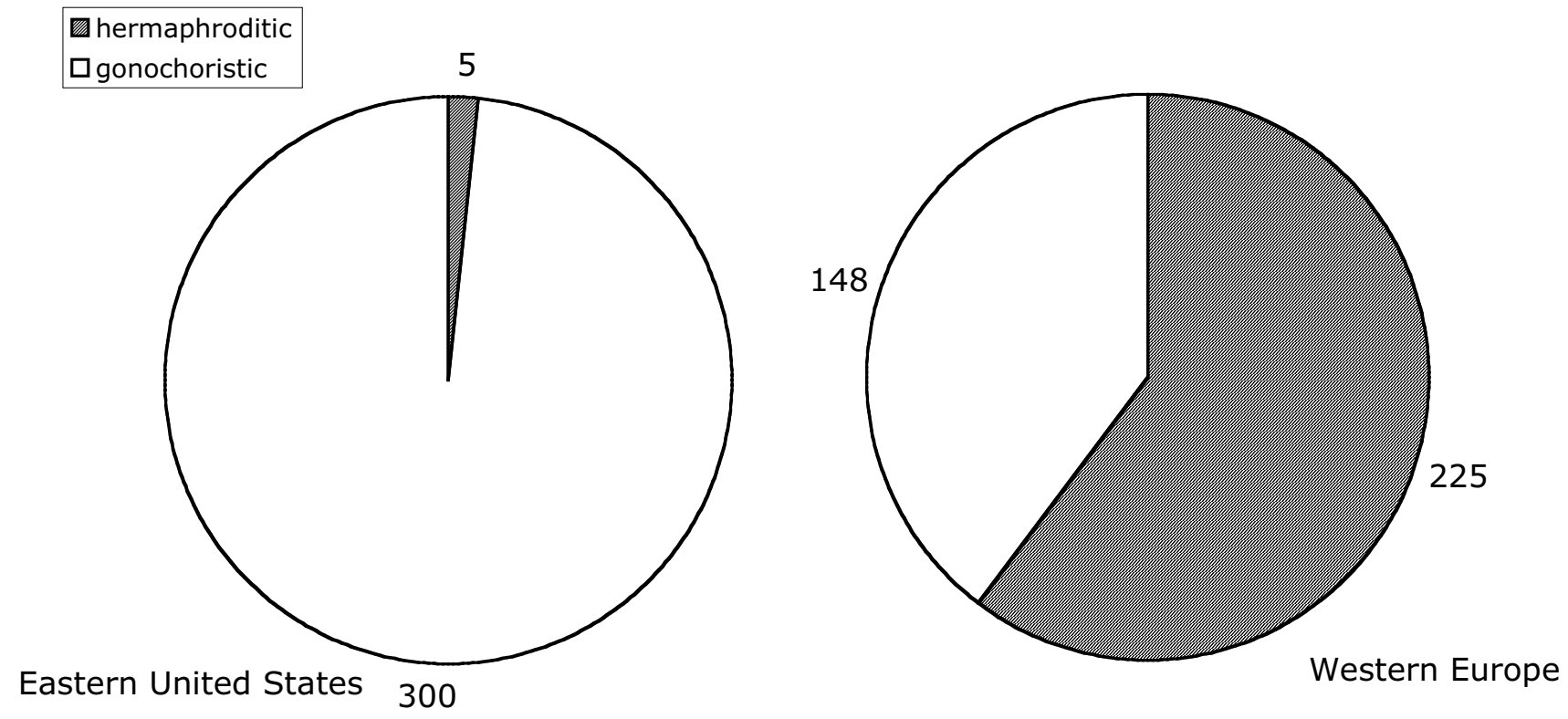

Figure 3

Pie charts indicating the ratio of gonochoristic (white) to hermaphroditic (grey) Pristionchus isolates in the Eastern US and Western Europe.

The Pristionchus species from the US form a phylogenetic clade together with P. maupasi

To determine if the Pristionchus biogeography would match species phylogeny we incorporated the North American species into the phylogenetic framework of the genus Pristionchus with a representative of the closely related genus Koerneria as outgroup (Fig. 4). Interestingly, $P$. aerivorus, $P$. pseudaerivorus n. sp., P. pauli n. sp., P. marianneae $\mathrm{n}$. sp. and $P$. americanus $\mathrm{n}$. $\mathrm{sp}$. form a single clade and are much more closely related to one another than the species found in Europe. P. aerivorus, $P$. pseudaerivorus n. sp. and $P$. americanus $\mathrm{n}$. sp. are the most closely related species and differ in only one out of 471 base pairs in their SSU sequence (Fig. 2). Surprisingly, the cockchafer-associated hermaphroditic species $P$. maupasi from Europe belongs to the same clade and carries an SSU sequence identical to the $P$. aerivorus sequence (Figs. 2, 4). A more detailed analysis including several ribosomal protein encoding nuclear genes distinguishes the two species and indicates that $P$. aerivorus and $P$. pseudaerivorus $\mathrm{n}$. sp. are the two most closely related species and that $P$. maupasi is the sister taxon to the $P$. aerivorus/P. pseudaerivorus $\mathrm{n}$. $\mathrm{sp}$. species pair (Fig. 5). Specifically, P. aerivorus and P. pseudaerivorus n. sp. differ in 19 nucleotides of the concatenated sequences of the rpl-26, rpl-28 and $r p s-14$ genes. In contrast, $P$. maupasi and $P$. aerivorus differ in 31 nucleotides and P. maupasi and P. pseudaerivorus n. sp. differ in 33 nucleotides of the corresponding sequences (Fig. 5). $P$. americanus $\mathrm{n}$. sp. and $P$. marianneae $\mathrm{n}$. sp. show even more nucleotide differences to the other species (Fig. 5). Thus, the investigated genes allow us to clearly distinguish these four species.

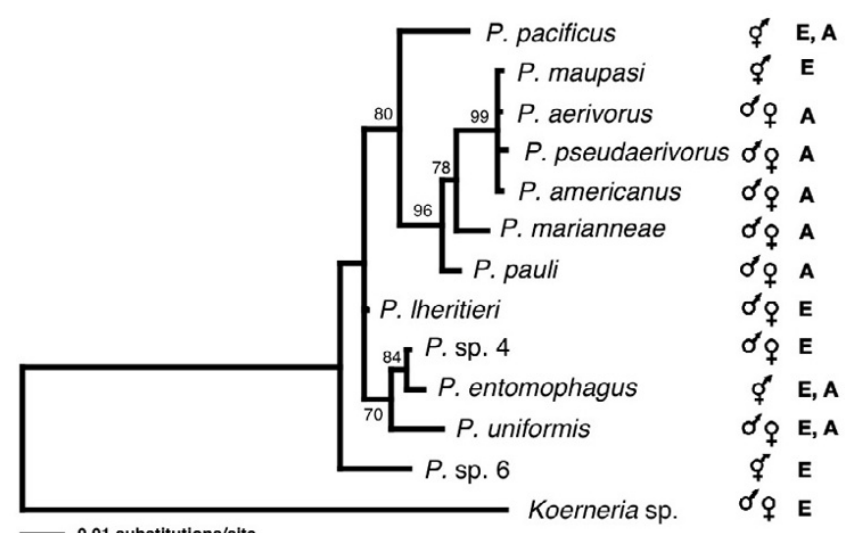

\section{Figure 4}

Phylogenic maximum likelihood tree based on SSU sequences of the genus Pristionchus. As outgroup the sequence of Koerneria sp. was included as the closest related genus to Pristionchus. A single best tree was obtained using the Kimura 2-parameter model (Kimura 1980) with Ts/Tv= 1,4727 , equal base frequencies, and a $\gamma$-correction with shape parameter $\alpha=0,238 \mathrm{I}$. Numbers at nodes indicate bootstrap values after 1000 replications. E, species observed in Western Europe; A, species observed in North-America (this study). 

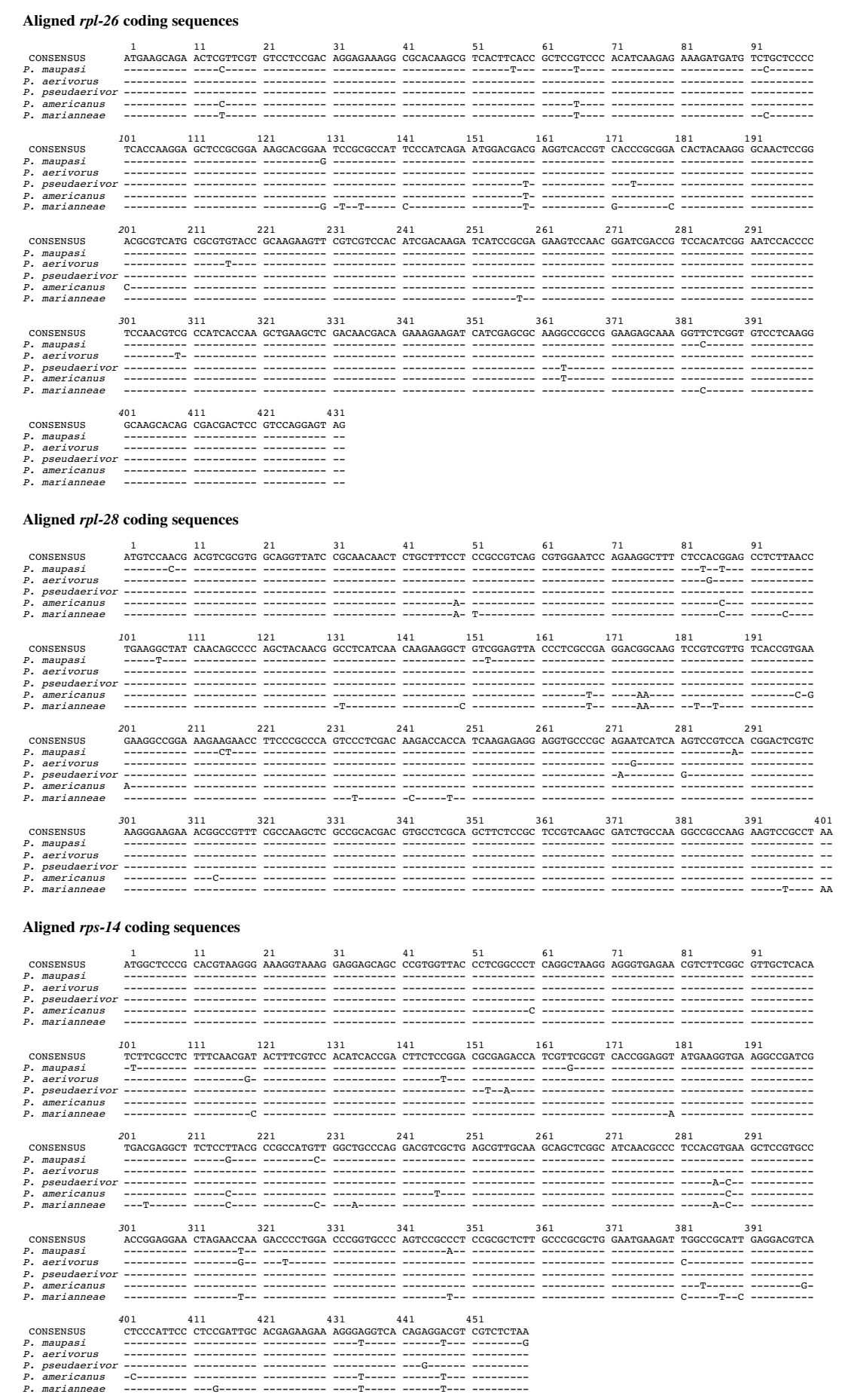

\section{Figure 5}

Alignment of the coding sequences of the ribosomal protein genes $r p l-26, r p l-28$, and $r p s-14$ of $P$. maupasi, $P$. aerivorus, $P$. pseudaerivorus, $P$. americanus, and $P$. marianneae. Dashes (-) indicate identity to the majority consensus sequence at the top. 


\section{P. aerivorus and P. pseudaerivorus n. sp. follow Haldane's rule}

The unusually high DNA sequence similarity between $P$. aerivorus and $P$. pseudaerivorus $\mathrm{n}$. $\mathrm{sp}$. suggests that they result from a recent speciation event. Therefore, these two species might still possess the potential to mate and form hybrid offspring. To obtain support for this hypothesis, we carried out cross-species mating experiments and found a strong case of Haldane's rule (Fig. 6). Haldane's rule states that in hybrids between diverging species the sterile absent or underrepresented offspring is of the heterogametic sex [11]. We found F1 hybrids in 12 of 24 crosses between $P$. aerivorus and $P$. pseudaerivorus n. $\mathrm{sp}$. and all of the F1 hybrid animals were phenotypically female (Fig. 6A). Specifically, F1 hybrids were obtained after reciprocal crosses of $\mathrm{P}$. pseudaerivorus $\mathrm{n}$. $\mathrm{sp}$. from Texas with four strains of $P$. aerivorus. In contrast, $P$. pseudaerivorus $\mathrm{n}$. sp. from Nebraska produced $\mathrm{F} 1$ hybrids only when males were used for mating with $P$. aerivorus females. Another P. pseudaerivorus n. sp. strain from Lincoln, Nebraska (LNE) did not produce F1 hybrids with any of the $P$. aerivorus strains. Thus, the occurrence of species hybrids is highly strain-specific and does not correlate

\begin{tabular}{|c|c|c|c|c|c|c|c|}
\hline & $\begin{array}{c}P . \text { aer } \\
\text { NY }\end{array}$ & $\begin{array}{c}P . \text { aer } \\
\mathrm{OH}\end{array}$ & $\begin{array}{c}P . \text { aer } \\
\text { TX }\end{array}$ & $\begin{array}{l}P . \text { aer } \\
\text { NE }\end{array}$ & $\begin{array}{c}P . p s e u \\
\text { LNE }\end{array}$ & $\begin{array}{c}P . p s e u \\
\text { TX }\end{array}$ & $\begin{array}{c}P . p s e u \\
\text { NE }\end{array}$ \\
\hline $\begin{array}{l}\text { P. aer } \\
\text { NY }\end{array}$ & $\begin{array}{c}319 \\
(148: 152)\end{array}$ & $\begin{array}{c}436 \\
(192: 187)\end{array}$ & $\begin{array}{c}261 \\
(74: 76)\end{array}$ & $\begin{array}{c}415 \\
(197: 201)\end{array}$ & $\begin{array}{c}274 \\
(0: 0)\end{array}$ & $\begin{array}{c}174 \\
(70: 0)\end{array}$ & $\begin{array}{c}256 \\
(30: 0)\end{array}$ \\
\hline $\begin{array}{c}\text { P.aer } \\
\mathrm{OH}\end{array}$ & $\begin{array}{c}531 \\
(241: 227)\end{array}$ & $\begin{array}{c}372 \\
(162: 166)\end{array}$ & $\begin{array}{c}335 \\
(152: 149)\end{array}$ & $\begin{array}{c}421 \\
(186: 197)\end{array}$ & $\begin{array}{l}135 \\
(0: 0)\end{array}$ & $\begin{array}{c}301 \\
(235: 0)\end{array}$ & $\begin{array}{c}231 \\
(11: 0)\end{array}$ \\
\hline $\begin{array}{l}\text { P.aer } \\
\text { TX }\end{array}$ & $\begin{array}{c}429 \\
(191: 187)\end{array}$ & $\begin{array}{c}295 \\
(16: 15)\end{array}$ & $\begin{array}{c}313 \\
(127: 131)\end{array}$ & $\begin{array}{c}334 \\
(148: 143)\end{array}$ & $\begin{array}{c}201 \\
(0: 0)\end{array}$ & $\begin{array}{c}133 \\
(8: 0)\end{array}$ & $\begin{array}{c}376 \\
(35: 0)\end{array}$ \\
\hline $\begin{array}{l}\text { P.aer } \\
\text { NE }\end{array}$ & $\begin{array}{c}326 \\
(152: 147)\end{array}$ & $\begin{array}{c}219 \\
(100: 102)\end{array}$ & $\begin{array}{c}187 \\
(52: 55)\end{array}$ & $\begin{array}{c}133 \\
(62: 60)\end{array}$ & $\begin{array}{c}131 \\
(0: 0)\end{array}$ & $\begin{array}{c}181 \\
(2: 0)\end{array}$ & $\begin{array}{c}210 \\
(5: 0)\end{array}$ \\
\hline $\begin{array}{c}\text { P. pseu } \\
\text { LNE }\end{array}$ & $\begin{array}{c}80 \\
(0: 0)\end{array}$ & $\begin{array}{l}120 \\
(0: 0)\end{array}$ & $\begin{array}{l}161 \\
(0: 0)\end{array}$ & $\begin{array}{c}80 \\
(0: 0)\end{array}$ & $\begin{array}{c}179 \\
(82: 79)\end{array}$ & $\begin{array}{c}39 \\
(18: 17)\end{array}$ & $\begin{array}{c}201 \\
(92: 94)\end{array}$ \\
\hline $\begin{array}{c}\text { P. pseu } \\
\text { TX }\end{array}$ & $\begin{array}{c}60 \\
(5: 0)\end{array}$ & $\begin{array}{c}274 \\
(93: 0)\end{array}$ & $\begin{array}{c}188 \\
(117: 0)\end{array}$ & $\begin{array}{c}71 \\
(47: 0)\end{array}$ & $\begin{array}{c}215 \\
(107: 97)\end{array}$ & $\begin{array}{c}184 \\
(85: 83)\end{array}$ & $\begin{array}{c}257 \\
(117: 112)\end{array}$ \\
\hline $\begin{array}{c}P . p s e u \\
\text { NE }\end{array}$ & $\begin{array}{c}287 \\
(0: 0)\end{array}$ & $\begin{array}{c}293 \\
(0: 0)\end{array}$ & $\begin{array}{c}269 \\
(0: 0)\end{array}$ & $\begin{array}{l}215 \\
(0: 0)\end{array}$ & $\begin{array}{c}294 \\
(146: 140)\end{array}$ & $\begin{array}{c}275 \\
(140: 121)\end{array}$ & $\begin{array}{c}272 \\
(127: 121)\end{array}$ \\
\hline
\end{tabular}

B

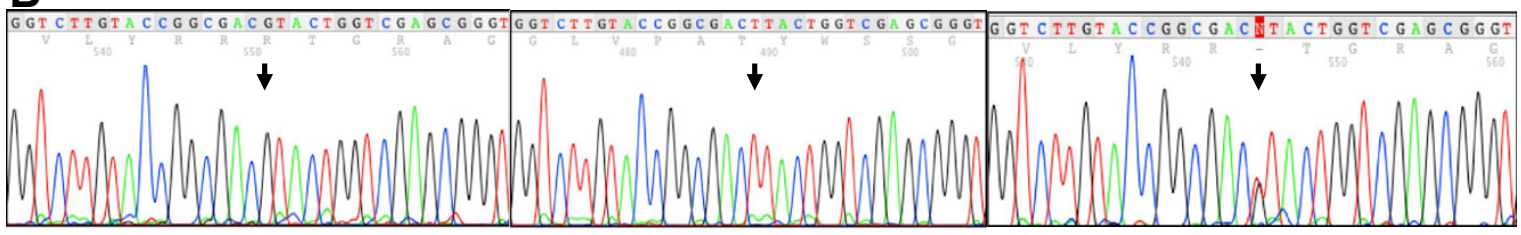

$P$. aerivorus

P. pseudaerivorus

F1 hybrid

Figure 6

FI hybrids of $\mathbf{P}$. aerivorus and $\boldsymbol{P}$. pseudaerivorus $\mathbf{n}$. sp. follow Haldane's rule. (A) Results of crosses between four strains of $P$. aerivorus (P. aer) from New York (NY), Ohio (OH), Texas (TX) and Nebraska (NE) and three strains of $P$. pseudaerivorus n. sp. (P. pseu) from Texas (TX), Indian Cave, Nebraska (NE) and Lincoln, Nebraska (LNE). Each strain was crossed with all other strains in a reciprocal manner. Columns represent female animals and rows represent males used for crosses. Mating was performed in triplicate, placing one virgin female and one male on a plate. Numbers show the total of eggs laid by one female. In brackets, the number of eggs that developed into phenotypic female vs. male progeny is indicated. The difference between the upper number and the sum of the numbers in brackets is accounted for by unfertilized eggs and embryonic lethality commonly observed after crosses within and between animals of these two species. The given numbers represent the result of the experiment with the highest number of offspring. (B) SSU sequence profile of $P$. aerivorus, $P$. pseudaerivorus n. sp. and a hybrid between the two species. 
with the geographic origin of the strains used in the analysis.

The primary signal in P. pacificus and C. elegans sex determination is the ratio of the set of $\mathrm{X}$ chromosomes to autosomes [1]. Animals with two X chromosomes develop as females (XX), whereas animals with a single X chromosome develop as males (XO). Theoretically, the absence of males among the F1 hybrid animals could result from the death of the putative XO animals or the sexual transformation of these animals into females. The latter scenario was observed in crosses of Caenorhabditis remanei with Caenorhabditis briggsae [16].

Additional support for the results of the laboratory crosses came from genotyped Pristionchus nematodes from wild scarab beetles. We found two cases of hybrids between $P$. aerivorus and $P$. pseudaerivorus $\mathrm{n}$. sp. emerging from individual beetles (Fig. 6B). Genotyping of other Pristionchus individuals from the same two beetles revealed that they carried both $P$. aerivorus and $P$. pseudaerivorus $\mathrm{n}$. sp., suggesting that the observed hybrids are the result of crossspecies fertilization (Fig. 6B). However, both hybrid animals were isolated more than a week after the beetle was placed on the petri dish. Therefore, it remains unknown if the observed hybrids came from the generation that lived on the beetle or whether it originated from fertilization in the laboratory. Taken together, $P$. aerivorus and $P$. pseudaerivorus $\mathrm{n}$. sp. co-exist on the same beetles in nature, they can form hybrids and laboratory-derived F1 hybrids follow Haldane's rule. In addition, both species have a similar geographic distribution in our sampling.

\section{The Colorado potato beetle hosts the same Pristionchus species in North America and Europe}

Finally, we wanted to know if Pristionchus nematodes occur in association with the CPB Leptinotarsa decemlineata in the United States. Our analysis of CPB in Europe had indicated that one species, $P$. uniformis, infests these beetles with high specificity [8]. The СРB is a pest species that originated in Mexico, where it extended its range of host plants from the wild solanaceae buffalo bur (Solanum rostratum) to include the potato (Solanum tuberosum). It migrated further north to the United States and was first described in Colorado in 1811. Spreading towards the East it reached the Atlantic coast in 1874 and was first reported in Europe in $1877[17,18]$.

We collected CPB from two different locations in Ohio and New York State and found Pristionchus nematodes with an infestation rate of up to $60 \%$ (Table 1 ). Sequence analysis and mating experiments revealed that all of these isolates belong to $P$. uniformis, the same species that is found on European CPB. Thus, in contrast to scarab beetles, the CPB hosts the same (and only one) Pristionchus species on both continents, $P$. uniformis. Given the recent invasion of the CPB to Europe we speculate that $P$. uniformis was introduced to Europe together with its beetle vector, the $\mathrm{CPB}$, at the end of the 19th century.

\section{Discussion}

We have shown that the Pristionchus species associated with scarab beetles in the Eastern United States are different from those found in Western Europe. The four predominant American species P. aerivorus, P. pseudaerivorus n. sp., $P$. marianneae n. sp. and $P$. pauli n. sp. are all unknown from Western Europe. In general, there is some preference of certain Pristionchus nematodes for a specific beetle. However, the nematode - beetle association is not striktly species-specific, an observation that is similar to what has been observed in our study in Europe [8]. This very interesting and important issue awaits further analysis, including more comprehensive studies on additional continents and exhaustive samplings of one particular continent.

One surprising observation of our surveys in the United States and Europe is the difference in the mode of reproduction observed between the two continents. While the two predominant Pristionchus species on European scarab beetles are hermaphroditic, the four predominant American species, representing $98 \%$ of the American isolates, are gonochoristic. We speculate that the evolution of hermaphroditism is a chance event that occurs with a very low probability. Despite this fact, the Pristionchus phylogeny presented in this study strongly suggests that the evolution of hermaphroditism has occurred multiple times independently: The hermaphroditic species $P$. pacificus, $P$. maupasi and $P$. entomophagus belong to three different clades of the genus and all of them have gonochoristic sister species (Fig. 4). Two different explanations can account for this pattern. First, speciation of hermaphroditic species might be absent or at least not very frequent. Alternativley, more frequent extinctions of hermaphroditic lineages than gonochoristic ones can also explain the observed patterns. The latter hypothesis is further supported by the fact that hermaphroditism is mostly observed in terminal lineages. Similar results have been obtained for rhabditid species of the genus Caenorhabditis [19].

The satellite organism $P$. pacificus represents an independent clade in the Pristionchus phylogeny with only three isolates from scarab beetles from Ohio, Nebraska and Massachusetts. P. pacificus does not seem to be a common species on scarab beetles in the United States, a finding that raises two possibilities. First, P. pacificus occurs in the United States, but not in association with the beetles that were investigated in this study. Second, $P$. pacificus repre- 
sents a species that has invaded North America recently and is not yet very common.

Several observations provide a first hint that the North American Pristionchus species are the result of relatively recent speciation events. The four most common beetleassociated species form a single clade in the phylogenetic tree. The only European species in this clade is P. maupasi, indicating that there is no complete biogeographic separation. Furthermore, this observation suggests that $P$. maupasi derives from a lineage that dispersed to Europe from North America. P. aerivorus and P. pseudaerivorus n. sp. coexist on the same beetle and cross-species matings were observed under laboratory conditions following Haldane's rule. All F1 hybrid animals were sterile females. We speculate that the effect of recessive deleterious alleles in the heterogametic hybrids causes inviability of males, a phenomenon known as dominance theory [20]. Given the easiness with which Pristionchus strains can be obtained at various places in the United States, Pristionchus nematodes provide an interesting model system to study if sympatric speciation occurs in nematodes and to study speciation and hybridization processes in general.

Finally, our studies of the CPB in the United States and Europe suggest a case of a species invasion. The introduction of the American CPB to Europe represents one of the first cases in which the invasion of an agricultural pest species was well documented. Recent studies have revealed that the genetic diversity of the CPB is much higher in North America than in Europe [21]. This observation is consistent with the assumption that the original invasion was due to a small number or even a single founder event. The fact that the CPB in the United States and Europe hosts the same nematode, P. uniformis, strongly suggests that $P$. uniformis was introduced into Europe with its beetle vector. With more $P$. uniformis isolates in hand from both continents we can start to address the question whether the genetic variability of European $P$. uniformis populations is reduced when compared to that of American populations. More generally, such studies can provide an important model for nematode species invasions across continents. In this context it is important to note that the case of Pristionchus is not unique for nematode invasions by insect vectors. One recent case is of high commercial interest. The pine wood nematode Bursaphelenchus xylophilus is a major pathogen of conifers and has recently been introduced to Europe by its vector, the beetle Monochamus galloprovincialis [22].

In summary, the observations of the Pristionchus species pattern on scarab beetles and the $\mathrm{CPB}$, as well as the easiness and frequency with which these nematodes can be isolated, indicates the potential of this nematode group for studying speciation, biodiversity, biogeography and species invasion on a global scale. When future samplings provide a global pattern of Pristionchus species and associations, the combination of field studies with genetic manipulation under laboratory conditions will allow functional investigations into nematode biodiversity and biogeography.

\section{Conclusion}

We describe the Pristionchus - beetle association in the Eastern United States and show striking evolutionary and ecological patterns. Most Pristionchus isolates from American scarab beetles belong to five species, all of which differ from the European species. The two most closely related species, $P$. aerivorus and $P$. pseudaerivorus $\mathrm{n}$. sp., follow Haldane's rule. The Colorado potato beetle is associated with the same species, $P$. uniformis in the United States and Europe, suggesting that $P$. uniformis was introduced to Europe together with its beetle vector. Together, the Pristionchus - beetle association provides a powerful tool for studying speciation, biodiversity, biogeography and species invasion on a global scale.

\section{Materials and methods Isolation of nematodes}

We collected different beetles at adult stage using sweeping nets, blacklight traps and pitfall traps baited with dung. The beetles were transferred to the lab alive, sacrificed by cutting them in half transversely, and put on NGM agar plates ( $6 \mathrm{~cm}$ diameter) seeded with $300 \mu \mathrm{l}$ of the slowly growing $E$. coli strain OP50. The plates were checked daily using a Zeiss Stemi 2000 dissecting scope over a period of one to three weeks for emerging and reproducing nematodes. From the emerging nematodes we produced isogenic lines by transferring single gravid females or hermaphrodites to new plates. To see whether the isolated nematodes belonged to gonochoristic or hermaphroditic species, virgin larvae were singled out onto plates. The presence of offspring indicated that they represent a hermaphroditic species.

Emerging nematodes were determined to family level with a Zeiss Stemi 2000 dissecting scope and to genus level with a Zeiss Axioplan 2 microscope using the key by Sudhaus and Fürst von Lieven [9]. For determination several worms were transferred onto microscopic slides covered with a $0.5 \mathrm{~mm}$ thick layer of $5 \%$ agar and either immobilized by heating the slide over an open flame to about $60^{\circ} \mathrm{C}$ for a few seconds or anesthesized with sodium azide. Within the genus Pristionchus many species can not be identified by morphological methods. We therefore chose to use molecular tools and mating experiments with reference strains to distinguish the different species. 
We have originally isolated up to three isogenic female lines per beetle and have processed them for sequence analysis. In nearly all cases, these isogenic female lines had identical SSU sequences. The exceptions were the observed hybrids between $P$. aerivorus and $P$. pseudaerivorus $\mathrm{n}$. sp. described above, and two cases where isogenic female lines of $P$. aerivorus and $P$. pseudaerivorus or $P$. aerivorus and $P$. marianneae were derived from the same beetle. When the SSU sequences of different isogenic female lines from the same beetle were identical, only one isolate was further considered. Throughout the text (and in the Tables and Figures), we consider only one of these identical isolates per beetle. In particular, the numbers and frequencies provided in Table 1 and Figure 3 consider only one of these isolates. In Table 1, beetle individuals from the different sampling sites are pooled. There was little variation in incidence of Pristionchus species on beetles among sampling sites.

\section{Molecular species identification}

Molecular species identification was done using the small subunit rRNA gene (SSU) as described before [8]. In short, genomic DNA from single nematodes was prepared using the $\mathrm{NaOH}$ digestion procedure described by Floyd et al. [23]. A single worm was transferred to $20 \mu \mathrm{l}$ of $0.25 \mathrm{M}$ $\mathrm{NaOH}$, incubated overnight at $25^{\circ} \mathrm{C}$ and heated to $99^{\circ} \mathrm{C}$ for $3 \mathrm{~min}$ before $4 \mu \mathrm{l}$ of $1 \mathrm{M} \mathrm{HC1}, 10 \mu \mathrm{l}$ of $0.5 \mathrm{M}$ Tris-HCl (pH 8.0) and $5 \mu$ of $2 \%$ Triton X-100 were added. The mixture was heated to $99^{\circ} \mathrm{C}$ for $3 \mathrm{~min}$, frozen at $-20^{\circ} \mathrm{C}$ and reheated at $99^{\circ} \mathrm{C}$ for further $3 \mathrm{~min}$. Two microliters of this extract were used for subsequent polymerase chain reaction (PCR).

A $1 \mathrm{~kb}$ fragment of the SSU was amplified by PCR using the primers SSU18A (5'-AAAGATTAAGCCATGCATG-3') and SSU26R (5'- CATTCTTGGCAAATGCTTTCG-3') $[23,24]$. The reactions were performed in $25 \mu \mathrm{l}$ of $1 \times$ PCR buffer (Amersham Biosciences, Freiburg, Germany) containing $2.5 \mathrm{mM}$ of $\mathrm{MgCl}_{2}, 0.16 \mathrm{mM}$ of each deoxynucleoside triphosphate, $0.5 \mu \mathrm{M}$ of each primer, $2 \mu \mathrm{l}$ of the lysate, and 2 units of Taq DNA polymerase (Amersham). The reactions were started by initial denaturation at $95^{\circ} \mathrm{C}$ for $2 \mathrm{~min}$ in a PTC-200 (MJ Research, Biozym, Hess. Oldendorf, Germany) or T gradient (Biometra, Göttingen, Germany) thermocycler, followed by 35 to 40 cycles of denaturation at $95^{\circ} \mathrm{C}$ for $15 \mathrm{sec}$, primer annealing at $50^{\circ} \mathrm{C}$ for $15 \mathrm{sec}$, and extension at $72^{\circ} \mathrm{C}$ for $2 \mathrm{~min}$. A final incubation step at $72^{\circ} \mathrm{C}$ for 7 min concluded the reaction. PCR products were purified by the Qiagen PCR product gel extraction kit (Qiagen, Hilden, Germany). Approximately $500 \mathrm{bp}$ of the 5 '-terminal end were sequenced using the primer SSU9R (5'-AGCTGGAATTACCGCGGCTG-3') and the Big Dye terminator protocol (Applied Biosystems, Darmstadt, Germany).
Sequences were aligned manually using the Seqpup $0.6 \mathrm{f}$ software for Macintosh [25]. The substitution model for the reconstruction of phylogenetic relationships was selected by the hierarchical likelihood ratio test as implemented in the Modeltest 3.7 software [26]. The selected substitution model corresponds to the Kimura 2-parameter model [27] with $\mathrm{Ts} / \mathrm{Tv}=1.4727$, equal base frequencies, and a $\gamma$-correction with shape parameter $\alpha=0.2381$.

\section{Phylogenetic analysis}

Phylogenetic trees were determined using the heuristic search algorithm under the maximum likehood (ML) criterion using PAUP*4.0blo program [28]. Trees were rooted by the Koerneria sp. sequence as outgroup. Neighbour joining (NJ, [29]) and maximum parsimony (MP) trees were drawn by the same program. Alignment gaps were eliminated from the analysis. The topological stability of the trees was assessed by 1000 bootstrap replications [30].

\section{Mating experiments}

To confirm the species identification by the molecular sequence of a novel isolate we performed mating experiments with the reference strain of the respective species (see below for definitions). Five virgin females were put on a plate with a small spot of OP50 together with five males of the reference strain of a certain species. On a second plate we picked the opposite sexes of the two strains to test for reciprocity. If there was no offspring after one week, the experiments were repeated two more times. If fertile offspring occurred we considered the two strains to belong to the same species.

\section{Isolate and strain definitions}

We use the following definitions to distinguish "isolates" and "strains". An isolate is an isogenic female line, which is derived from a beetle sample and subjected to molecular and experimental analysis. After species identification we established one isolate per species and location as a strain. The strains are permanently cultured in the lab, have a strain number and are also kept as frozen stocks. For each new species designated by molecular sequence analysis and mating experiments, one strain was defined as a reference strain (see below).

\section{Assigning names to reference strains}

According to the designation of reference strains, the 285 isolates obtained from American scarab beetle material fell into seven Pristionchus species, two of which were already cultured in our lab ( $P$. pacificus, reference strain PS312 and P. entomophagus ref. strain RS0144). The other five could not be identified. We found the morphometric data of the most common of the unidentified species to coincide with the description of the only North American Pristionchus species listed in the catalog provided by Sud- 
haus and Fürst von Lieven [9], namely $P$. aerivorus. The other four species are novel and are described based on morphometric analysis, SSU sequence analysis and mating experiments (Fig. 2, Table 2 and species diagnoses). In total, the following eight Pristionchus species were obtained from scarab beetles (seven species) and the Colorado potato beetle (one species) in North America:

Pristionchus entomophagus (Steiner, 1929) (ref. str. RS0144)

Pristionchus pacificus Sommer, Carta, Kim \& Sternberg, 1996 (ref. str. PS312)

Pristionchus uniformis Fedorko \& Stanuszek, 1971 (ref. str. RS0141)

Pristionchus aerivorus (Cobb in Merrill \& Ford, 1916) (ref. str. RS5106)

Pristionchus pseudaerivorus n. sp. Herrmann, Mayer \& Sommer 2006 (ref. str. RS5139)

Pristionchus marianneae n. sp. Herrmann, Mayer \& Sommer 2006 (ref. str. RS5108)

Pristionchus pauli n. sp. Herrmann, Mayer \& Sommer 2006 (ref. str. RS5130)

Pristionchus americanus n. sp. Herrmann, Mayer \& Sommer 2006 (ref. str. RS5140)

\section{Comparison of ribosomal proteins}

In order to obtain nuclear protein coding genes to distinguish $P$. americanus $\mathrm{n}$. sp. from its sister species $P$. aerivorus, $P$. pseudaerivorus $\mathrm{n}$. sp. and P. maupasi we isolated total RNA from 50 to $100 \mu \mathrm{g}$ of nematodes using the TRI$\mathrm{ZOL}$ reagent (Invitrogen). The RNA was reverse transcribed into cDNA with the help of the Omniscript reverse transcriptase kit (Qiagen, Hilden, Germany) and the primer RH5620 (5'-GAAGATCTAGAGCGGCCGCCCTTTTTTTTTTTTTTT-3'). Based on EST data from SL1-transspliced genes from European Pristionchus species (unpublished data) we designed generic RT-PCR primers for Pristionchus ribosomal protein genes (WM8220, 5'-TCGACAACGACAGAAAGAAGA-3', rpl-26, sense; WM8221，5'-ACGGAGTCRTCGCTGTRCTTGC-3', rpl-26, antisense; WM8263, 5'-CCGTCAGCGYGGMATCCAGAAG-3', rpl-28, sense; WM8264， 5'-GCTGGASGGAGCGGAGRAGCTG-3', rpl-28, antisense; WM8114, 5'GCYCAYATYTTCGCYTCTTTCAA-3', rps-14, sense; WM8113, 5'-GGRGTCTTNGTTCTRGTTCCTC-3', rps-14, antisense) and used them to synthesize the complete transcript in two overlapping fragments by PCR. The SL1-specific primer BJ234 (5'-GGTTTAATTACCCAAGTTTGAG-3') was used with the antisense primers to obtain the $5^{\prime}$ part of the transcripts and the combination of RH5620 and the sense primers to obtain the 3' parts. The PCR was performed with the help of the HotStar Taq DNA polymerase kit (Qiagen) including the $\mathrm{Q}$ solution in the reaction mix. Conditions were initial activation of the enzyme at $95^{\circ} \mathrm{C}$ for $15 \mathrm{~min}$, followed by 40 cycles of denaturation at $94^{\circ} \mathrm{C}$ for $30 \mathrm{sec}$, primer annealing at $50^{\circ} \mathrm{C}$ for $30 \mathrm{sec}$, and primer extention at $72^{\circ} \mathrm{C}$ for $3 \mathrm{~min}$. The reaction was completed by an incubation at $72^{\circ} \mathrm{C}$ for $10 \mathrm{~min}$. PCR fragments were gel purified using the Wizard SV gel purification kit (Promega) and sequenced directly using the PCR primers.

\section{Authors' contributions}

MH carried out all of the field work and the generation of isogenic female lines and crosses. WEM generated isogenic female lines and did all of the molecular analysis. RJS designed and discussed the experiments with $\mathrm{MH}$ and WEM and wrote, together with MH and WEM the manuscript.

\section{Acknowledgements}

We thank Paul Robbins and Antony Shelton at the Geneva Campus of Cornell University, the „Team Scarab“ Brett Ratcliffe, Mary Liz Jameson and Matt Paulsen at the University of Nebraska, Michael Klein and Casey Hoy for their help. We thank H. Haussmann for maintaining of Pristionchus strains and Dr. R. Hong and M. Riebesell for critically reading this manuscript.

\section{References}

I. Hong RL, Sommer RJ: Pristionchus pacificus - a well-rounded nematode. BioEssays 2006, 28:65I-659.

2. Sommer RJ, Carta L, Kim S-Y, Sternberg PW: Morphological, genetic and molecular description of Pristionchus pacificus sp. n. (Nematoda: Neodiplogastridae). Fundamental and Applied Nematology 1996, 19:51 I-521.

3. Sommer RJ: WormBook, doi/l0.1895/wormbook. I.7.I [http:// www.wormbook.org]. December 14; 2005

4. Srinivasan J, Sinz W, Lanz C, Brand A, Nandakumar R, Raddatz G, Witte H, Keller H, Kipping I, Pires-daSilva A, Jesse T, Millare J, de Both M, Schuster SC, Sommer RJ: A BAC-based genetic linkage map of the nematode Pristionchus pacificus. Genetics 2002, 162:129-134.

5. Srinivasan J, Sinz W, Jesse T, Wiggers-Perebolte L, Jansen K, Buntjer $J$, van der Meulen M, Sommer RJ: An integrated physical and genetic map of the nematode Pristionchus pacificus. Mol Gen Genomics 2003, 269:715-722.

6. Barrière A, Félix M-A: High local genetic diversity and low outcrossing rate in Caenorhabditis elegans natural populations. CurrBiol 2005, I 5: I I76-I I84.

7. Kiontke K, Sudhaus W: WormBook, doil/ 0.1895/wormbook. I.7.I [http://www.wormbook.org]. December 6; 2005

8. Herrmann M, Mayer WE, Sommer RJ: Nematodes of the genus Pristionchus are closely associated with scarab beetles and the Colorado potato beetle in Western Europe. Zoology 2006, 109:96-I08.

9. Sudhaus W, Fürst von Lieven A: A phylogenetic classification and catalogue of the Diplogastrina (Secernentea, Nematoda). J Nem Morph Syst 2003, 6:43-90.

10. Fedorko A, Stanuszek S: Pristionchus uniformis sp. n. (Nematoda, Rhabditida, Diplogasteridae) a fakultative parasite of Leptinotarsa decemlineata Say and Melolontha melolontha $L$. in Poland. Morphology and biology. Acta Parasitologica Polonica 1971, 19:95-II2. 
II. Haldane JBS: Sex-ratio and unisexual sterility in hybrid animals. J Genetics 1922, 12:101-109.

12. White RE: A Field Guide to Beetles of North America Boston: Houghton Mifflin Co.; 1983.

13. Srinivasan J, Pires-daSilva A, Guitierrez A, Zheng M, Jungblut B, Witte $H$, Schlak I, Sommer RJ: Microevolutionary analysis of the nematode genus Pristionchus suggests a recent evolution of redundant developmental mechanisms during vulva formation. Evolution and Development 2001, 3:229-240.

14. Fürst von Lieven A, Sudhaus W: Comparative and functional morphology of the buccal cavity of Diplogastrina (Nematoda) and a first outline of the phylogeny of this taxon. J Zool Sys and Evol Res 2000, 38:37-63.

15. Cobb NA, Merril JH, Ford AL: Life history and habits of two new nematodes parasitic in insects. J AgricRes 1916, 6:1 I5-127.

16. Baird SE: Haldane's rule by sexual transformation in Caenorhabditis. Genetics 2002, 161:1349-1353.

17. Gerstaecker A: Der Coloradokäfer und sein Auftreten in Deutschland Kassel: Fischer; 1877.

18. Jacques RL: The potato beetles Brill Academic Publishers; 1988.

19. Kiontke K, Gavin NP, Raynes Y, Roehrig C, Piano F, Fitch DHA: Caenorhabditis phylogeny predicts convergence of hermaphroditism and extensive intron loss. Proc Natl Acad Sci USA 2004. 101:9003-9008.

20. Orr HA: Haldane's rule. Annu Rev Ecol Syst 1997, 28:195-218.

21. Grapputo A, Boman S, Lindstrom L, Lyytinen A, Mappes J: The voyage of an invasive species across continents: genetic diversity of North American and European Colorado potato beetle populations. Mol Ecol 2005, 14:4207-4219.

22. Mota M, Vieira P, (Eds): The pinewood nematode, Bursaphelenchus xylophilus. In Proceedings of the workshop held in Évora: August I7-20, 200I. Nematology Monographs \& Perspectives Volume I. Brill Academic Publishers; 2004.

23. Floyd R, Abebe E, Papert A, Blaxter M: Molecular barcodes for soil nematode identification. Mol Ecol 2002, I I:839-850.

24. Blaxter ML, de Ley P, Garey JR, Liu LX, Scheldeman P, Vierstraete A, Vanfleteren JR, Mackey LY, Dorris M, Frisse LM, Vida JT, Thomas K: A molecular evolutionary framework for the phylum Nematoda. Nature 1998, 392:7I-75.

25. Gilbert DG: SeqPup version 0.6f: a biosequence editor and analysis application 1996 [http://iubio.bio.indiana.edu/soft/molbio].

26. Posada D, Crandall KA: Modeltest: testing the model of DNA substitution. Bioinformatics I998, I4:8I7-8I8.

27. Kimura $\mathrm{M}$ : A simple method for estimating evolutionary rates of base substitutions through comparative studies of nucleotide sequences. J Mol Evol 1980, 16: I II-I20.

28. Swofford DL: PAUP: Phylogenetic Analysis Using Parsimony (and other methods). Version 4.0b10 Sunderland, Massachusetts: Sinauer Associates; 2002.

29. Saitou N, Nei M: The neighbor-joining method: a new method for reconstructing phylogenetic trees. Mol Biol Evol 1987, 4:406-425.

30. Felsenstein J: Confidence limits on phylogenies: an approach using the bootstrap. Evolution 1985, 39:783-791.

\section{Publish with Bio Med Central and every scientist can read your work free of charge}

"BioMed Central will be the most significant development for disseminating the results of biomedical research in our lifetime. "

Sir Paul Nurse, Cancer Research UK

Your research papers will be:

- available free of charge to the entire biomedical community

- peer reviewed and published immediately upon acceptance

- cited in PubMed and archived on PubMed Central

- yours - you keep the copyright

Submit your manuscript here:

http://www.biomedcentral.com/info/publishing_adv.asp
BioMedcentral 